\title{
NEOLIBERALISMO MULTICULTURAL EN EL CHILE POSTDICTADURA: LA POLÍTICA INDÍGENA EN SALUD Y SUS EFECTOS EN COMUNIDADES MAPUCHES Y ATACAMEÑAS
}

\author{
MULTICULTURAL NEOLIBERALISM IN THE POST DICTATORSHIP CHILE: \\ INDIGENOUS HEALTH POLICY AND ITS EFFECTS ON MAPUCHE AND \\ ATACAMEÑO COMMUNITIES
}

\author{
Paola Bolados García ${ }^{1}$
}

\begin{abstract}
En este artículo analizamos el proceso de construcción del campo de la salud intercultural en Chile, asociado al nuevo marco ideológico-conceptual que hemos definido como neoliberalismo multicultural. Este contexto tiene como punto de inflexión la vuelta a la democracia a inicios de los años noventa y la continuidad del modelo económico impuesto durante el régimen dictatorial anterior. Paradoja que se traducirá en presiones desde la agencia estatal-trasnacional hacia las organizaciones indígenas, por incorporar las prácticas curativas indígenas al aparato público, fomentando así a su progresiva burocratización y neoliberalización. Finalmente examinamos los efectos colaterales de este tipo de intervenciones en salud en experiencias interculturales de organizaciones mapuches y atacameñas, principalmente en relación a la profesionalización del conocimiento indígena y la creación de expertos que este tipo de programas promovió.
\end{abstract}

Palabras claves: neoliberalismo multicultural, salud intercultural, mapuches y atacameños.

This article analyzes the formation of the field of intercultural health in Chile associated with the ideological-conceptual framework we have defined as multicultural neoliberalism. This context emerges with the restoration of democracy in the early 90 's and the continuity of the neoliberal economic model imposed during the previous dictatorship. Paradoxically, due to pressures on indigenous organizations, from state and transnational agencies, to incorporate indigenous healing practices into the public system, progressive bureaucratization and neoliberalization were fostered. Finally, the side effects of such interventions in health on Atacameño and Mapuche intercultural experiences were examined in relation to the professionalization of indigenous knowledge and the creation of experts promoted by these programs.

Key words: Multicultural neoliberalism, intercultural health, Mapuche and Atacameño.

Gran parte de los estudios sobre interculturalidad y multiculturalismo en Latinoamérica han estado marcados por aproximaciones constitucionalistas que han tendido a judicializar la problemática étnica (Sieder 2002). Esta corriente ha estado liderada por juristas y representantes de organizaciones que con éxito han introducido las discusiones sobre la diversidad cultural en la agenda de los organismos internacionales. En el caso de los pueblos indígenas, muchos evalúan los años 90 como la década ganada en cuanto a su reconocimiento y participación política en las reformas impulsadas durante ese período (Bengoa 2007). No obstante, otros observan que estos avances se han limitado a un reconocimiento formal y restringido de los derechos colectivos de estos pueblos, orientados a compatibilizar democracia política y libertad económica (Bolados 2010; Hale 2002; Paley 2001). En este sentido, ha predominado un multiculturalismo cuyas acciones se plantean como estrategias para la superación de la pobreza e inclusión social de las poblaciones indígenas excluidas por el sistema económico actual. Aunque el multiculturalismo está asociado a las reformas democratizadoras de los años noventa y a las luchas de los movimientos sociales de las décadas anteriores, sus antecedentes lo vinculan con la arremetida neoliberal que se impuso en el escenario internacional después de la Segunda Guerra Mundial.

En este contexto, el neoliberalismo se constituyó en una nueva hegemonía cultural cuyo proyecto social consistió en remodelar las relaciones entre Estado y sociedad (Taylor 2006), transformando a los individuos en consumidores cada vez más activos y autorregulados (Rose 2006). La década ganada se presenta entonces paradigmática respecto al avance de los procesos de democratización y participación indígena, por un lado, y la profundización y

1 Instituto de Investigaciones Arqueólogicas y Museo (IIAM), Universidad Católica del Norte, San Pedro de Atacama, Chile. paobolados@yahoo.com.ar 
consolidación del proyecto neoliberal por el otro. Esta "confluencia perversa", como sostiene Dagnino, radica en que ambos procesos, aunque parecen representar ideologías opuestas, requieren de una sociedad civil activa y comprometida (Dagnino 2006:402). Las políticas y/o programas culturales actuales se constituyen de esta manera, en la nueva ingeniería social (Breton 2003), cuyos efectos tienden a desligar al Estado de sus obligaciones tradicionales y responsabilizar a los ciudadanos en tanto consumidores de una ciudadanía cultural y/o diferenciada (Schild 2000).

Este proceso se canalizó vía agencias de desarrollo internacional, las cuales han cumplido la función de expandir y profundizar el modelo neoliberal a través de una lógica subsidiaria y focalizada dirigida a los sectores sociales potenciales de conflicto. En este marco ideológico-conceptual las comunidades indígenas son tratadas como grupos corporativos que deben ser objeto de intervenciones de gobierno orientadas a empoderar, responsabilizar y hacer participar en la promoción de su capital social. Este concepto es reelaborado y promovido especialmente por el Banco Mundial y otros organismos multilaterales como el Banco Interamericano de Desarrollo desde la década de los años ochenta, quienes propagan la idea del capital social como herramienta que los propios grupos excluidos pueden utilizar para su salida del subdesarrollo. En este sentido, consideramos que la utilización del término inter o multicultural está teniendo una función estratégica y política para las comunidades indígenas en su lucha por el reconocimiento, a la vez que sirve para introducir el discurso del neoliberalismo democrático que tiende a profundizar mecanismos de privatización y tercerización en las relaciones sociales.

En continuidad con esta idea, nuestra aproximación etnográfica estudia al multiculturalismo como un dispositivo de poder, el cual exige exploraciones críticas en relación al surgimiento de los nuevos espacios de participación y sus relaciones con las políticas económicas dirigidas a la apertura de nuevos mercados y grupos de consumidores. Esta situación se ha revelado particularmente compleja en aquellos contextos donde el interés del capitalismo global por la explotación de los recursos naturales ubicados en territorios indígenas devino en la apertura de lo que Watts denomina espacios gobernables de indigeneidad (Watts 2003:20). Estos espacios se conforman fundamentalmente en aquellos territorios donde las demandas indígenas e intereses transnacionales se enfrentan por la apropiación de los recursos medioambientales y en donde los diversos agentes, aun con grados de poder desiguales, ejercen presiones para obtener cuotas de participación y dominio sobre estos. En el caso de las poblaciones andinas de Chile, estas deben hacer frente a las presiones del Estado y el mercado por el control de los recursos minerales y geotérmicos. En el sur, la construcción de proyectos hidroeléctricos, así como la actividad de forestales y salmoneras, se presentan como la gran amenaza a la vida y salud de las poblaciones mapuches, pehuenches, lafquenches y williches. Se manifiestan asílos alcances y límites de las políticas multiculturales y el nuevo rol del Estado en tanto administrador de las diferencias que favorece determinadas expresiones de etnicidad -el buen étnico- y rechaza aquellas que ponen en riesgo la economía política impuesta por el sistema neoliberal (Hale 2002).

Coincidiendo en parte con lo que afirma el antropólogo norteamericano Charles Hale, lo que se ha puesto en marcha es una versión reducida del multiculturalismo. Esta se caracteriza por un discurso que promueve la expansión de derechos y de formas de ciudadanía cultural y/o diferenciada por un lado, mientras que por el otro, restringe y subordina aquellos derechos que entran en conflicto con los intereses económicos transnacionales. Esta nueva variante del multiculturalismo Hale la define como multiculturalismo neoliberal, comprendiéndola como el nuevo espacio abierto por las reformas sociales y culturales introducidas por el neoliberalismo y que se configuran en un escenario no siempre de confrontación entre comunidades indígenas, Estado y agencias de desarrollo global, sino también un ámbito de negociación favorable a sus demandas. Para efectos de comprender el caso chileno, deberíamos quizás entonces invertir la fórmula de Hale, planteando que lo que se implementó en Chile durante las últimas dos décadas, más que un multiculturalismo neoliberal es un neoliberalismo multicultural. Este se caracterizaría principalmente por representar más que una versión limitada del multiculturalismo, una versión extendida del neoliberalismo hacia campos socioculturales antes ignorados (Bolados 2010). Nos referimos a la incorporación de las prácticas terapéuticas indígenas en el campo de la salud intercultural y sus efectos en cuanto a su progresiva burocratización y neoliberalización en experiencias mapuches y atacameñas. 


\section{Formación del Campo de la Salud Intercultural en Chile}

Este nuevo marco ideológico y político comienza a configurarse en Chile con la vuelta de la democracia a comienzos de los años 90, a partir de la puesta en marcha de una política intercultural que fue profundizada en la década siguiente con la implementación de un programa multicultural de amplio alcance y cuantiosos recursos. Nos referimos al Programa de Desarrollo Integral para comunidades indígenas, mejor conocido por el nombre de Orígenes, el cual se marketeó como un programa de gobierno que no obstante significó un préstamo de casi 70 millones de dólares del Banco Interamericano de Desarrollo. El contrato de préstamo firmado el año 2001 fue aproximadamente por un monto total de 113 millones de dólares, los cuales serían distribuidos en cinco componentes: educación y salud intercultural, ámbito productivo, fortalecimiento institucional y mercadeo social. Debido a la novedad y complejidad del programa, Orígenes se estructuró en dos fases de implementación (2001-2006 y 2007-2009), teniendo como objetivo mejorar las condiciones de vida de los tres grupos indígenas del país (mapuche, aymara y atacameño) a través de dos ejes principales: la participación social y el desarrollo integral con identidad. El componente de salud intercultural del programa, que funcionó durante la primera fase, contempló entre sus objetivos "fortalecer la medicina indígena" y "promover la construcción de modelos de atención intercultural" entre los grupos indígenas beneficiados (Banco Interamericano de Desarrollo 2001). Sin embargo, como lo reconocen los agentes a cargo del diseño y de la ejecución del programa, su implementación es directamente vinculada con los propósitos de desmovilizar y apaciguar el conflicto indígena mapuche, el cual había nuevamente recrudecido a fines de la década de los años 90 con la construcción de la central hidroeléctrica Ralko en territorio pehuenche (Región del Bío-Bío).

La perspectiva de la salud intercultural como campo la adoptamos del antropólogo Guillaume Boccara, quien, tomando el concepto del sociólogo Pierre Bourdieu, define a la salud intercultural como un subcampo dentro del campo burocrático mayor que constituye la salud pública (Boccara 2007). Desde esta perspectiva, las prácticas terapéuticas indígenas se constituyeron en un capital en torno al cual agentes indígenas, estatales y multilaterales disputaron por convertirse en los agentes autorizados de este campo (Bourdieu y Wacquant 2005). En el caso de Chile, la participación social, la interculturalidad y el desarrollo integral con identidad se transformaron en los ejes de una lucha política por el control de los mecanismos de producción y representación social de las diferencias. A su vez, con la llegada del componente de salud de Orígenes, a nuestro entender se desplegaron estrategias orientadas a regular las prácticas curativas indígenas y desplazar el espacio terapéutico tradicional hacia formas y lugares instituidos por la burocracia estatal de la salud pública. Desde una perspectiva foucaultiana, se trata de un nuevo arte de gobierno (Foucault 2000), en el que el ethnos aparece tanto como una estrategia de incorporación de las minorías indígenas a las políticas neoliberales actuales, así como un mecanismo sociopolítico a través del cual regular la vida de estas poblaciones (Boccara 2007). Foucault llamó a este dispositivo biopoder, entendiendo por éste el modo cada vez más detallado y exhaustivo a través del cual se pretende regular la conducta, ya no sólo a través de técnicas disciplinarias sobre el cuerpo de los individuos (anatomopolítica), sino a través de tácticas dirigidas hacia la población (biopolítica). Esta nueva inclusión étnica se realiza a través de una reelaboración del concepto de capital social impulsada por las agencias de desarrollo global, las cuales propagan la idea de que el fortalecimiento del capital social genera ipso facto procesos democratizadores y de desarrollo más óptimos. Contradiciendo a la mayoría de las posiciones que afirman un retiro del Estado como parte fundamental de las políticas neoliberales, nuestra perspectiva sostiene que el Estado más que debilitarse en un contexto de globalización y transnacionalización se ha reorganizado a través de la política multicultural, interviniendo de manera novedosa en la incorporación de las poblaciones indígenas nacionales.

\section{Los orígenes de "Orígenes"}

El primer programa intercultural en salud en Chile surge en el año 1992, en un contexto favorable al reconocimiento de los pueblos originarios. Los compromisos asumidos por el entonces candidato presidencial Patricio Aylwin el año 1989 con las organizaciones indígenas en el Pacto Nueva Imperial y la conformación de la Comisión Especial de Pueblos Indígenas en los inicios de la transición 
democrática configuraron el escenario propicio para la formalización de este tipo de propuestas al interior del aparato público. Este escenario, potenciado por las acciones de organizaciones internacionales como la Organización Panamericana de la Salud, que buscaban desarrollar iniciativas participativas bajo las orientaciones de la atención primaria, asimismo las interpretaciones y alcances del Convenio N $^{\circ} 169$ de la OIT del año 1989 que se expresa específicamente a favor de la protección y fomento de los conocimientos medicinales de los pueblos indígenas, dieron pie a que experiencias locales en salud tuvieran por primera vez cabida en el ámbito de la política regional. Esta se materializó con la aparición del primer programa dirigido a la población mapuche en la Región de La Araucanía. Aunque este programa conocido como el PROMAP es expresión de inquietudes de profesionales de la salud y dirigentes mapuches anteriores a los años noventa, éstas logran formalizarse dentro de las estructuras de la política en salud recién en los inicios de la década de los 90. Año en que se realiza el encuentro de Winnipeg-Canadá donde por primera vez organismos internacionales expresan la necesidad de un reconocimiento y valoración concreta de las prácticas curativas indígenas. El objetivo del PROMAP desde sus inicios se concentra en mejorar la calidad de la atención de la población mapuche en los centros de salud, siendo sus ejes centrales la capacitación, la investigación, así como también el conocimiento comunitario y la docencia. La mayoría de este grupo de profesionales encontró en el espacio de la salud un lugar propicio desde el cual generar transformaciones después de un largo período caracterizado por las prácticas represivas del régimen dictatorial. Entre las primeras acciones que promovió el PROMAP estuvo la creación de las oficinas Amuldungun (año 1993) donde se formalizó la figura del facilitador intercultural. Esta surgió como una instancia mediadora entre usuarios del sistema médico formal y como una ayuda para superar los problemas de comunicación de algunos pacientes indígenas, la mayoría mujeres mayores de edad con dificultad para expresarse en español. Sin embargo, y como lo expresó la primera facilitadora intercultural en el primer encuentro nacional en Puerto Saavedra el año 1996, algunas de las experiencias mostraron a través del tiempo cómo el rol del facilitador fue rápidamente absorbido por la burocracia del sistema público de salud, quedando muchas veces limitado sólo a funciones administrativas. Durante los años 1996 a 1999 florecieron diversas iniciativas a lo largo del país, las cuales fueron canalizadas a través de encuentros, talleres y seminarios organizados por el PROMAP'. Entre ellas destacó el "Primer Encuentro Nacional de Salud y Pueblos Indígenas: Hacia una Política Nacional Intercultural en Salud" realizado el año 1996 en Puerto Saavedra, Región de La Araucanía. Muchos de quienes participaron en Puerto Saavedra consideran que en este encuentro se definieron los aspectos medulares de una propuesta nacional, coincidiendo en que después de Puerto Saavedra no hay nada nuevo. En estos encuentros se reúnen por primera vez funcionarios de la salud, dirigentes indígenas, terapeutas tradicionales, investigadores y docentes universitarios, organismos no gubernamentales, iglesias, etc., a debatir sobre un tema hasta ahora alejado del ámbito de las políticas públicas: el reconocimiento y valoración desde el sistema público de los sistemas médicos indígenas. Pese a las advertencias sobre los posibles errores que traería convertir experiencias locales en modelos nacionales por parte de los impulsores de estas iniciativas, el éxito del PROMAP se constituye para el Estado y varios organismos internacionales, en el ejemplo a seguir. De esta forma, se dio paso a un segundo momento del proceso de construcción del campo de la salud intercultural en Chile, el cual tuvo como característica la progresiva desvinculación de las demandas territoriales y medioambientales de la política de salud. La progresiva despolitización del tema salud se produce a la par de la puesta en marcha del programa nacional PESPI o Programa Especial Salud y Pueblos Indígenas, el cual emerge en un contexto efervescente con las experiencias de salud desarrolladas en el sur y un apoyo internacional que promueve la implementación de políticas multi o intercultural. Esta apuesta gubernamental inédita al interior del Ministerio de Salud se produce gracias al financiamiento y apoyo de organizaciones no gubernamentales y de cooperación internacional, las cuales confluyeron con la resolución $\mathrm{V}$ de la Organización Panamericana de la Salud que promueve la iniciativa "Salud y Pueblos Indígenas de las Américas". Este se planteó como meta "contribuir a lograr la equidad en las Américas en un contexto de reconocimiento y respeto de la diversidad cultural de los pueblos", buscando "el mejoramiento de la salud de los pueblos indígenas de la región de una manera integral y coordinada 
en el marco de la interculturalidad y el desarrollo humano" (Resolución V. OMS/OPS, en Alderete 2004).

En este sentido, la salud intercultural en el discurso global surge como un nuevo paradigma que busca reconocer que todos los sistemas médicos son limitados para resolver los actuales problemas de salud, admitiendo la existencia de otros sistemas de salud cuyos principios, especialistas, tratamientos y elementos corresponden a formas ancestrales de entender y practicar la medicina (Alderete 2004) ${ }^{2}$. Algunas experiencias de este tipo desarrolladas en Latinoamérica se sustentaron en programas de salud familiar y comunitaria (SAFIC) y/o los sistemas locales de salud (SILOS) promovidos por organismos como la misma Organización Panamericana de la Salud (OPS). En el caso de Chile, esta última iniciativa es considerada un antecedente directo del Programa Especial Salud y Pueblos Indígenas (PESPI), el cual aparece como consecuencia de una experiencia SILOS en Chile a inicios de la década de 1990 donde por primera vez surgen los debates sobre participación e interculturalidad. En el transcurso de este proceso, la interculturalidad en salud es reproducida bajo la conocida imagen de dos sistemas cuya intersección constituye el espacio de la interculturalidad. Una perspectiva construida por las organizaciones internacionales y propagada por agentes estatales que homologa sistema biomédico y sistema indígena, reduciendo la complejidad y dinamismo bajo la cual cada uno de estos sistemas encuentra legitimidad y vigen$\mathrm{cia}^{3}$. A nivel asistencial, la primera propuesta se concreta en la comuna de Padre de Las Casas en el hospital Makewe (Región de La Araucanía), que hasta entonces había estado en manos de la iglesia anglicana y el cual fue entregado el año 1999 en comodato a la Asociación Mapuche Makewe Pelale. Con esta experiencia pionera por primera vez se incorporaron formalmente las atenciones médicas tradicionales mapuches, constituyéndose en el primer hospital intercultural en Chile administrado por una organización indígena. Durante ese período la asociación, con apoyo del director del hospital, lleva adelante iniciativas que intentan poner en marcha la primera universidad indígena y un sistema de pasantías de carácter internacional ${ }^{4}$. Años después se cristalizaron otros dos proyectos liderados por organizaciones indígenas mapuches, entre ellas el centro de salud familiar Boroa Filulawen a cargo de la coordinadora de salud Boroa Filulawen y el centro de salud mapuche Ñi Lawentuwün a cargo de la asociación Newentuleaniñ ${ }^{5}$, creadas el 2003 y 2005 respectivamente. Estas experiencias, que recibieron el título de los elefantes blancos de la salud intercultural en Chile, en la medida que fueron creciendo en términos de inversión presupuestaria, fueron simultáneamente perdiendo autonomía al tener que alinearse a la cultura administrativa del Estado a fin de obtener los recursos ofrecidos por este. Este proceso Cuyul lo caracterizó como la burocratización de la salud intercultural en Chile (Cuyul 2008). Las propias encargadas de dirigir el centro de medicina mapuche del hospital intercultural Nueva Imperial, Doraliza Millalén y Juana Calluil, señalaron en un encuentro organizado por la CEPAL el año 2007, a una década de Puerto Saavedra, que los principales obstáculos en el trabajo en salud con el Estado continuaban siendo:

La falta de espacios de participación, desigualdad en los recursos, carencia de lenguaje común, no aceptación de la diversidad, paternalismo institucional, relación asimétrica y una difícil relación con los médicos alópatas (CEPAL 2007:12).

Lo que se produce entonces en palabras de Cuyul es que:

La medicina mapuche va poco a poco perdiendo autonomía...condicionándose peligrosa y progresivamente por la intervención estatal sin resolver el tema de fondo que es el territorio y las posibilidades de desenvolvimiento en el mismo (Cuyul 2008:2) $)^{6}$.

Pese a los logros que se observan, los avances de esta política se perciben todavía limitados respecto a las demandas étnicas en Chile, específicamente en relación a las radicales contradicciones y ambigüedades de la política indígena y medioambiental del país. Asimismo el programa reveló tener una importancia marginal en la política de salud nacional, lo cual se tradujo tanto en la lentitud como en el incumplimiento de los instrumentos legales comprometidos a las organizaciones indígenas en el último período: la falta de reconocimiento constitucional, la tardía ratificación del Convenio $\mathrm{N}^{\mathrm{o}} 169$ y el no reconocimiento legal de la medicina indígena que durante este período fue testigo del 
reconocimiento de las medicinas alternativas al interior del sistema de salud público. Estos y otros factores caracterizaron a este período como de un importante retroceso en materia indígena en general, y en el área de la salud en particular en un contexto en que La Araucanía está incendiada ${ }^{7}$ y donde era preciso calmar el conflicto mapuche recrudecido con la construcción de $\operatorname{Ralko}^{8}$. La visualización de estos procesos condujo al distanciamiento de quienes iniciaron estas experiencias, varios de los cuales retomaron la problemática de la ruralidad como eje de las inequidades en salud. No obstante, los conflictos en el ámbito de la salud intercultural recrudecieron con la implementación del megaprograma multicultural conocido como Orígenes. Con este programa y según a nuestro entender se dio inicio a una tercera y última etapa en el proceso de formación del campo de la salud intercultural en Chile, donde los énfasis explícitos -participación y etnodesarrollo- fueron contrarrestados por los acentos burocratizadores y neoliberalizantes que este programa introdujo.

\section{Burocratizando y Neoliberalizando la Medicina Indígena: Acciones y Reacciones}

A casi una década del PROMAP y cinco años del PESPI, el componente de salud de Orígenes aparece como un programa participativo e innovador en áreas como capacitación e intersectorialidad, donde paradójicamente desde el inicio se presentaron agudos conflictos entre el Ministerio de Salud, ejecutor del componente de salud, y el Ministerio de Planificación, ejecutor de la primera fase de Orígenes. Algunos reconocen que sus recursos permitieron una mejor coordinación y ordenación de las políticas públicas y el aumento considerable del presupuesto en las áreas en las que intervino. Sin embargo, existe consenso respecto a que sus efectos negativos se concentraron en el agotamiento de los equipos y organizaciones indígenas por la gigantesca carga burocrática vinculada a Orígenes. Provocó un doble esfuerzo y discurso en relación a la salud intercultural, generando que quienes venían realizando un trabajo anterior a Orígenes quedaran paulatinamente marginados del proceso. El efecto dólar había generado enormes expectativas tanto en las instituciones que hasta ahora venían trabajando más con voluntad que con recursos, como en las organizaciones indígenas que accedieron a administrar proyectos propios con cifras nunca antes vistas. Por estas razones Orígenes desde los inicios experimentó una enorme resistencia y rechazo, ya sea desde el antiguo equipo de PROMAP como desde los diversos equipos de salud donde venía trabajando el PESPI. Ante el escenario de rechazo, Orígenes debió apelar a las históricas fidelidades políticas con las que se instaló la democracia en Chile: "había que ser críticos pero no había que ser desleal" resonó en los oídos de uno de sus protagonistas las palabras del entonces presidente Ricardo Lagos. Sin embargo, el efecto Orígenes en territorio mapuche se sintió con especial intensidad al ser la sede de las primeras y más importantes experiencias en el tema de salud intercultural en Chile. La falta de consideración al camino transitado fue considerada como una falta de respeto a los procesos locales que ya se habían llevado a cabo'. El programa se percibió como una hecatombe que pese a su formato moderno y eficiente reprodujo el paternalismo indigenista característico del período desarrollista anterior ${ }^{10}$. En otros aspectos el programa fue criticado por su nivel de improvisación y el fuerte autoritarismo que contradecía sus objetivos de constituirse en un programa participativo (en su diseño no existió participación indígena). Sin embargo, los efectos indirectos pero más devastadores estuvieron en el desmantelamiento de las movilizaciones que se iniciaron en el año 1997 y que con ayuda de los medios de comunicación impusieron una imagen del mapuche terrorista/criminal, principal obstáculo al progreso del país. Varios de quienes participaron de la implementación del componente de salud del programa destacan los efectos esquizoides de esta nueva ingeniería social. La oferta estatal de Orígenes centrada en la propiedad individual convocó cada vez más a que la gente se desuniera fortaleciendo una lógica individualista y promoviendo la competencia por acceder a los recursos dispuestos por Orígenes. De esta forma, no sólo se intenta reterritorializar a las comunidades sino también sus formas de representatividad, ya que los criterios de elección estaban limitados a la nueva calidad de sujeto jurídico otorgada y consagrada por el Estado multicultural: "¿qué pasaba ahora si uno de los especialistas indígenas, llámese yatiri, machi... no pertenecía a estas comunidades?" se pregunta una de las antropólogas involucradas en las experiencias del norte de Chile. Pese a los intentos burocratizadores y neoliberalizantes sobre estas megaexperiencias mapuches, comunidades lafquenches y wichilles se resistieron a estas presiones, rechazando separar 
el ámbito de la salud de las demandas territoriales (Boccara 2004).

No obstante los efectos del componente de salud de Orígenes en el territorio mapuche, la apertura de este campo años más tarde en el área atacameña del Salar se tradujo paradójicamente en una revitalización y visibilización de las demandas en relación a la salud ancestral. Este proceso favoreció la incorporación de nuevos agentes indígenas que dieron vida a la primera asociación de sanadores, mientras que paralelamente agudizó los conflictos entre agentes estatales, quienes iniciaron una disputa progresiva por adjudicarse la autoridad en tanto representantes autorizados de los diversos organismos del Estado multicultural. En este contexto, las definiciones sobre ¿qué es lo intercultural y cómo se entiende la participación social y el desarrollo integral con identidad promovidos por el programa? constituyeron el eje de las luchas y debates generados con la llegada del componente de salud intercultural al área atacameña. En este sentido, las organizaciones locales resistieron a las presiones de Orígenes y contestaron a sus imposiciones a través de diversas estrategias. Una de estas estrategias fue la constitución de la primera asociación de terapeutas indígenas que se legitimó como una instancia de interlocución directa ante el Estado en este tema. Con esta estrategia consiguieron en varias oportunidades obtener el control del campo de la interculturalidad e impedir que avanzaran las negociaciones individuales fuertemente fomentadas por los agentes estatales encargados de implementar el programa. Paralelamente, la asociación surge como respuesta a los primeros conflictos con el programa, el cual establecía determinadas formas de representaciones política y étnica, desconociendo y marginando a otras dadas por las propias organizaciones. Este fue el caso de la mesa de salud, primera instancia de participación local que intentó resistir a las estructuras verticalistas del programa. Por lo mismo y desde sus inicios, ésta se constituyó en una instancia fuertemente resistida tanto por otros sectores indígenas con los cuales disputaban el campo de la salud intercultural, como por las agencias y servicios estatales que buscaban permanentemente incorporarlas al ámbito burocratizado de la estructura etnopolítica abierta con la legislación de los años noventa. Finalmente, la resistencia de la asociación de terapeutas a incorporarse a estos espacios burocratizados terminó desconociéndola y marginándola del espacio político de la salud.
El segundo momento de conflicto se produce cuando este grupo de sanadores y dirigentes asociados decide participar en una experiencia dentro del centro de salud local. Intentando obtener el mismo estatus médico que propone el sistema, se inicia una experiencia, la cual desde el principio experimenta resistencias desde el poder local que administra la salud en la comuna, así como también de parte de las instituciones y servicios estatales. Esta experiencia es el resultado de las gestiones de la asociación al interior del nuevo espacio de participación social abierto por el centro de salud local denominado Consejo de Desarrollo Local. Finalmente, la asociación y luego de admitir las dificultades de trabajar con el sistema público altamente protocolizado, decide construir una sala de atenciones para sus sanadores. Con fondos del programa y en dependencias municipales, se construye la Sala Curativa Likana sin tomar en cuenta las formas, requerimientos y adecuaciones del sistema de atención indígena. Los sanadores que comienzan a atender allí comienzan a advertir las dificultades de trabajar fuera del contexto terapéutico tradicional, el cual no dejaba espacio para las dimensiones sagradas y rituales involucradas en los sistemas de sanación indígena. En este período las luchas por desburocratizar el campo de la salud son dirigidas por los propios sanadores quienes hasta ese momento habían tenido una participación indirecta y marginal en este proceso. Desde ahora, la sala se constituye en un espacio de rituales exorcizantes de espíritus que se encuentran en ese lugar. Se requiere un periodo de limpieza y rogativas que traigan las lluvias e impidan la desertificación del desierto evitando que desaparezcan las yerbas medicinales y los pocos hombres y mujeres que todavía cultivan estas prácticas. Los sanadores deciden volver a sus espacios terapéuticos tradicionales. Su sabiduría los vuelca a replegarse a sus sitios sagrados, abandonando la sala donde sienten que expusieron e hicieron públicas sus prácticas. Tanto las organizaciones indígenas locales como las estatales mostraron dificultad para iniciar un camino de diálogo y reconocimiento. Las acciones de la política en salud y pueblos indígenas quedaron finalmente congeladas en el territorio, revelando todavía contener visiones exógenas y equívocas acerca del desarrollo con identidad y la participación indígena.

Los efectos neoliberalizantes que trajo el componente de salud del programa Orígenes y sus intentos por burocratizar las prácticas curativas 
indígenas locales, mostraron simultáneamente dos efectos colaterales: la aparición de un nuevo sistema de autorización y experticia y, con este, la privatización y tercerización de los servicios culturales asociados al programa. Respecto al primer aspecto, los expertos de este campo emergente no fueron sólo los sanadores o curanderos, sino una serie de otros agentes que vía una formación etnoburocrática, se configuran en los nuevos expertos de la interculturalidad. Dirigentes, profesionales de la salud y de las ciencias sociales se legitiman como agentes autorizados de este campo de la salud intercultural y participan en el proceso de sistematización y profesionalización del conocimiento indígena (Laurie et al. 2005). En este proceso y como un segundo efecto, los equipos locales son marginados de los procesos de producción de conocimiento. Ahora se compran servicios y todos, menos la consultora que se adjudica el proyecto, ponen en marcha mecanismos de auditoría y fiscalización. La consultoría se constituye en un agente externo por lo general privado o privatizado que ofrece estos servicios, convirtiendo a los expertos o sabios comunitarios en informantes claves en sus propuestas. Pese a que el sistema de producción de conocimiento promovido por Orígenes y su componente de salud intercultural se presentó altamente técnico y científico, al poco tiempo mostró que las decisiones básicamente eran tomadas desde criterios político-partidistas con una importante dosis clientelar (Bello 2007). Las prácticas políticas y profesionales anteriores comenzaron a verse como un proyecto de hippies y trasnochados que pasaban mucho tiempo en terreno, pero que carecían de una sólida formación teórica. De un paradigma donde el conocimiento era construido participativamente y legitimado dentro de los espacios de las organizaciones sociales, políticas y culturales, pasamos a un paradigma elitista donde los nuevos lugares de producción de conocimiento se centraron en las sedes de organismos internacionales, universidades, centros de investigación y consultoras externas especializadas.

\section{Palabras de Cierre}

El neoliberalismo multicultural implementado por Orígenes y su componente de salud en Chile, revelaron ser un mecanismo sociopolítico e ideológico complejo y de diversas aristas. Después de casi cuatro décadas de neoliberalismo en Chile, éste muestra su capacidad de rehacerse revelando ser un proyecto cultural, político y social de amplio alcance. De una comprensión del mismo como exclusivamente un sistema económico asociado a la desregulación del trabajo, la privatización de los recursos medioambientales y la creencia en el funcionamiento autónomo del mercado, éste revela sus dimensiones sociales y culturales orientadas a sustituir las relaciones entre Estado y sociedad bajo la lógica del consumo. La nueva soberanía del mercado parece imponerse a través de dispositivos y tácticas más positivas y generativas que buscan evitar una regulación excesiva y el ejercicio de la violencia extrema. No obstante existe el riesgo permanente de cruzar estas fronteras cuando los intereses del capitalismo se ven amenazados. Los hechos del último período en el sur de Chile muestran las limitaciones para regular el histórico conflicto de tierras en territorios mapuches con programas de etnodesarrollo como Orígenes y donde las políticas interculturales resultan ineficaces ante sus pretensiones de un desarrollo integral con identidad. En otros contextos no obstante, sus efectos parecen menos desfavorables transformándose en una nueva oportunidad política, aunque siempre limitada en lo que se refiere al reconocimiento y la multiculturalidad que demandan las poblaciones originarias. Este parece ser el caso atacameño analizado, en el que el nuevo campo de la salud intercultural se constituyó en un escenario político propicio para instalar demandas socioétnicas pendientes.

Agradecimientos: A FONDECYT y el proyecto postdoctorado $\mathrm{N}^{\mathrm{o}} 3120062$. A Eduardo Rapiman y su familia, quienes me acogieron durante mi estadía de campo en Temuco. También a los profesionales del PROMAP: Jaime Ibacache, Mario Castro y Jorge Neira y los dirigentes Miriam Torres, Sergio Cuyul y Andrés Cuyul pertenecientes a las organizaciones indígenas williches. A las colegas antropólogas Margarita Sáez, Alejandra Leython y Malva Pedreros. A Guillaume Boccara con el que compartimos importante tramos de este trabajo. También extiendo este agradecimiento especialmente a la asociación de cultores y colaboradores de la medicina ancestral licanantay y quechua. Finalmente agradezco a los evaluadores quienes han aportado interesantes críticas para mejorar este texto. 


\section{Referencias Citadas}

Alderete, E. 2004. Saludy Pueblos Indígenas. Abya Yala, Quito.

Bello, A. 2007. El programa orígenes y la política pública del gobierno de Lagos hacia los pueblos indígenas. En El gobierno de Lagos, los Pueblos Indígenas y el "Nuevo Trato". Las Paradojas de la Democracia Chilena, editado por N. Yáñez y J. Aylwin, pp. 193-220. Ediciones LOM, Santiago.

Bengoa, J. 2007. La Emergencia Indígena en América Latina. Fondo de Cultura Económica, Santiago.

Banco Interamericano de Desarrollo [BID] 2001. Documento de préstamo BID/Gobierno de Chile. BID, Santiago.

Boccara, G. 2004. Del buen gobierno en territorio mapuche. Notas acerca de una experiencia en salud complementaria. Cuadernos de Antropología Social 20:113-129.

- - - - 2007. Etnogubernamentalidad: la formación del campo de la salud intercultural en Chile. Chungara Revista de Antropología Chilena 39:185-207.

Bolados, P. 2010. Neoliberalismo Multicultural en el Chile Democrático: Gubernamentalizando la Salud Atacameña a través de la Participación y el Etnodesarrollo. Tesis para optar el grado de doctora en antropología. Universidad Católica del Norte-Universidad de Tarapacá, San Pedro de Atacama.

Bourdieu, P. y L. Wacquant 2005. Una Invitación a la Sociología Reflexiva. Siglo XXI Editores, Buenos Aires-México.

Breton, V. 2003. Neoliberalismo, etnicidad y etnofagia en América Latina: La experiencia de los Andes del Ecuador. Meeting of Latin American Studies Association. Dallas, Texas.

Comisión Económica para América Latina [CEPAL] 2007. Informe Seminario-Taller Pueblos Indígenas de América Latina: Políticas y Programas de salud, ¿cuánto y cómo se ha avanzado?, Santiago.

Cuyul, A. 2008. La burocratización de la salud intercultural (octubre). Del neo-asistencialismo al autogobierno mapuche en salud. www.mapuexpress.net (mayo 2010)
Dagnino, E. 2006. Concepciones de la ciudadanía en Brasil: proyectos políticos en disputa. En Ciudadanía, Sociedad Civil y Participación Política, compilado por I. Cheresky, pp. 387-410. Miño y Dávila editores, Buenos Aires.

División de desarrollo de sistemas y servicios de salud OMS/OPS 1998. Memoria del primer encuentro nacional salud y pueblos indígenas: hacia una política intercultural nacional en salud. www.paho.org/spanish/ad/ths/os/indi_7esp.pdf (octubre 2009).

Foucault, M. 2000. Power, editado por J. Faubion, pp. 200-221. The New Press, New York.

Hale, C. 2002. Does multiculturalism menace? governance, cultural rights and the politics of identity in Guatemala. Journal of Latin American Studies 34:485-524.

Laurie, N., R. Andolina y S. Radcliffe 2005. Ethnodevelopment: Social movements, creating experts and professionalising indigenous knowledge in Ecuador. Antipode 37:470-496.

Paley, J. 2001. Marketing Democracy. Power and Social Movement in Post-dictatorship Chile. University of California Press, Berkeley, Los Angeles.

Rose, N. 2006. Governing 'advanced' liberal democracies. En The Anthropology of the State, editado por A. Sharma y A. Gupta, pp. 144-162. Blackwell Publishing. USA, UK, Australia.

Sieder, R. 2002. Multiculturalism in Latin America: Indigenous Rights, Diversity and Democracy. Palgrave, Basingstoke, New York.

Schild, V. 2000. Neo-liberalism's new gendered market citizens: the "civilizing" dimension of social programmes in Chile. Citizenship Studies 4:275-305.

Taylor, M. 2006. From Pinochet to the "Third Way": Neoliberalism and Social Transformation in Chile. Pluto Press, London.

Watts, M. 2003. Development and governmentality. Singapore Journal of Tropical Geography 24:6-34.

\section{Notas}

1 Entre las iniciativas que en ese período surgen están los seminarios de medicina intercultural en Arica de los años 1994 y 1996, así como las experiencias en comunas urbanas de Santiago. Nos referimos a la organización Pulawen que comenzó una experiencia de atención complementaria en la comuna de La Pintana y en el consultorio Yazigi de Lo Prado, ambas ubicadas en la ciudad de Santiago.

2 Algunos de los factores que inciden en la situación de salud de la población indígena destaca la deforestación de árboles nativos y su reconversión por especies exóticas, los efectos de la radiación por los desechos nucleares en algunas partes de Centro América, la crisis de recursos hídricos provocada por las actividades de la minería y mega proyectos hídricos, el aumento de la actividad turística en territorios indígenas trayendo nuevos grupos migratorios e inversiones extranjeras, la extracción de recursos naturales, nuevos proyectos urbanísticos y otros procesos como la inmigración, urbanización y desruralización de la sociedad indígena. A estos agentes de deterioro de la situación de salud de las poblaciones indígenas es preciso agregar los problemas de acceso a los sistemas de salud formal, donde la presencia de un médico llega a 1 cada 10.000 habitantes en algunos lugares (Alderete 2004).

3 Esta imagen se difunde en varias formas y lugares como la representación legítima de la interculturalidad. Con esta figura, lo que se hace es asimilar el campo médico indígena a las formas y categorías de la biomedicina que actualmente predomina en la política pública de salud. A raíz de estas interpretaciones el yatiri o curandero es homologado al médico, el espiritista al psicólogo, el partero al matrón y el compositor de huesos al kinesiólogo.

4 Este período de florecimiento se traduce también en una vasta producción e investigación impulsadas por los equipos iniciadores de este camino. Principalmente destacamos los 
trabajos colectivos dirigidos por Jaime Ibacache, así como los aportados por el equipo de atención primaria de la Universidad de La Frontera liderados por Lucas Citarelli de la cooperación italiana. Participa de este equipo Ana María Oyarce quien posteriormente realizará aportes junto a Malva Pedreros en temas de epidemiología sociocultural desde la CEPAL.

5 Tanto el Hospital de Makewe, Nueva Imperial como del Centro Boroa Filulawen actualmente se financian con fondos del Estado a través de un decreto especial firmado con el Fondo Nacional de Salud (FONASA).

6 Ya desde el año 2003 existen antecedentes del rechazo de un sector de las organizaciones indígenas mapuches ante la separación de la situación de salud de la población indígena y el tema territorial por parte de las instituciones y programas estatales. Este conflicto se hizo particularmente explícito cuando a pedido del gobierno de Lagos se conformó la Comisión Verdad Histórica y Nuevo Trato. La disidencia frente a este trabajo realizado por "especialistas de la cultura" (historiadores, antropólogos y arqueólogos) dio como resultado la creación de una Comisión de Trabajo Autónomo Mapuche más conocida como la COTAM. En el documento oficial elaborado por esta comisión se hace una denuncia explícita a este punto sosteniendo la interdependencia entre demandas de salud y demandas territoriales.
7 La expresión describe los últimos años del período del presidente democratacristiano Eduardo Frei, el que desde su gobierno y a través de diversos ministerios inició los diálogos comunales. Estos se consideran los antecedentes directos del programa Orígenes.

8 El proyecto para la construcción de una hidroeléctrica ejecutado por la empresa transnacional Endesa consiguió la adquisición de 3.750 hectáreas en la localidad de Ralko, en la zona del Alto Bío-Bío, lo que significó la reubicación de 500 personas pertenecientes a comunidades pehuenches, las cuales y después de una larga y dura lucha contra el Estado de Chile y las presiones de la empresa, cedieron sus terrenos a cambio de títulos de tierras de baja calidad agrícola.

9 Tomando las expresiones de uno de los iniciadores del PROMAP cuando describe cómo llega Orígenes a la Región de La Araucanía.

10 Refiriéndose especialmente al componente productivo que continuó trabajando en la línea paternalista de dar cosas, lo cual deterioró mucho el trabajo participativo y autogestionante de las comunidades. Se recuerda en este sentido la entrega casi inmediata de recursos que se realizó por familia y no por comunidad u organización, generando una enorme división y competencia al interior de las asociaciones y comunidades indígenas en las cuales intervino Orígenes. 